\title{
Morphometric Studies of the Colon in the Albino Rat
}

\author{
Korzerzer, R. $\mathbf{M}^{\mathbf{1}}$, Shinbo $\mathbf{J}^{\mathbf{1}}$. \\ ${ }^{1,2}$ Federal University of Agriculture, Makurdi
}

\begin{abstract}
This study was carried out to evaluate the morphometric variations of the colon of female albino rats at different age groups. Fifteen female albino rats were divided into three groups of 5 rats each. Group A included rats at the age of two months, group $B$ included rats aged four months and Group C rats were aged 6 months. After 14 days of acclimatization, the animals were sacrificed by decapitation under $20 \mathrm{mg} / \mathrm{kg}$ of thiopental sodium intraperitonially, then a thoraco-lumbar incision was made to expose the digestive tract and the colon dissected out for anatomical studies. Grossly, the weight and length of colons increased with age and weight of the animals. Gross morphometry showed that colon length increased with age. Histomorphometry showed that the colon crypt width and height also increased with age. This probably can be attributed to the fact that there is increased demand for nutrients with age. In conclusion, this study was able to show that the colon increased in size with age and rate of colon growth was pronounced at six months old albino rat due to the presence of intense colon fission. This points out to the reason why the risk for colon cancer increases with age.
\end{abstract}

Keywords Colon, Morphometry

\section{Introduction}

The colon is the last part of the digestive system. It plays a role in extracting water and salt from solid wastes before they are eliminated from the body and is the site in which flora-aided fermentation of unabsorbed material occurs.

Cancer incidence in the large intestine is known to be higher than that of the small intestine, which has been attributed to greater bacterial density of the large intestine compared with that in the small intestine (Tjalsma, H., Boleij, A., Marchesi, J.R and Dutilh, B.E.2012). Intestinal pathologies, especially of the colon are very common (Fodde, 2002).Although transgenic mice are commonly used in intestinal cancer research, data regarding the morphology of healthy intestinal mucosa in mice are still scanty. The existing morphological studies of the intestine of rodents are limited only to assessment of the tumours that occur (Fodde, 2002). The characteristics of anatomically healthy colon would be an important element in describing the pathological processes of the colon. Moreover, the prevention of cancer is mainly directed to the normal tissue in order to protect it from the development of a lesion. In view of this, we decided to describe the morphological, histological and histomorphometric characteristics of the albino rat colon.

Laboratory animals are suitable subjects for many modern experimental and biomedical research including metabolic studies, tumor and cancer investigation, anatomical, and biochemical research, and experimental transplantation. Frequently, the laboratory mammals are also used as animal models for veterinary and human research. The knowledge of anatomical variations is important for experimental investigation and surgical practice. The investigation of anatomy, comprising the morphology and histology of the colon in albino rat is needed inorder to detect an altered structure.

Morphological changes of the intestine has more often been used in the assessment of intestinal pathology (Weser and Tawil, 1976 ; Izukura et al., 1992). The colon plays a major role in both digestion and absorption, processes various complex carbohydrates and, to a lesser extent, proteins that prove resistant to digestion and absorption in the more proximal intestine (Rombeau, 2003). Unlike the small intestine, the colon salvages nutrients from these products via fermentation. Fermentation occurs by means of the saccarolytic and proteolytic members of the over 400 species of bacteria, the majority of which are obligate anaerobes, present within the colon (Nordgaard, 1998). Approximately $10 \%$ of ingested carbohydrates enter the cecum as undigested material (Bharucha and Camilleri, 2007). This research could be used as a model for groups involved in comparative experimental research using the albino rat as a model for human problems such as cancer of the colon, diagnosis, and assessment of intestinal pathology and in studies of intestinal development, the morphological and biochemical changes that occur largely in structures related to the exchange and absorption processes, such as villi, crypts, enterocytes and microvilli.

The aim of this research is to conduct morphometric studies on the colon of the albino rat at different age groups

The objective of this study:

To study the gross morphometry of the colon of female albino rats at different age groups

\section{Materials and Methods}

\begin{abstract}
Animal source
Fifteen (15) apparently healthy female albino rats, aged two, four and six months of age were purchased from the College of Health Science, Benue state University, Makurdi, and transported by means of constructed cages to the research laboratory of the Department of Veterinary Anatomy, Federal University of Agriculture, Makurdi.
\end{abstract}

\section{Experimental Design}

The animals were divided into three groups of five animals in each group as group A, B and C according to their ages at two, four and six months respectively and acclimatized for 


\section{International Journal of Science and Research (IJSR) \\ ISSN (Online): 2319-7064}

Index Copernicus Value (2015): 78.96 | Impact Factor (2015): 6.391

14 days. During period of acclimatization, animals were fed pelletised grower and water ad libitum. Each animal was weighed and the weight recorded. Animals were sacrificed using chloroform gaseous anaesthesia. A ventral midline incision was done to identify and transect the colon for routine histology.

\section{Histological Technique}

The organs were weighed, labelled and fixed for 48 hours in $10 \%$ formaldehyde. Prior to weighing and fixing, each organ was examined critically and the excess fat and tissues removed, the organs were thereafter dabbed with a clean towel before taking the weights. Dehydration was done through a series of graded alcohol $(70 \%, 80 \%, 90 \%, 95 \%$ and $100 \%$ ). This was then cleared with xylene and infiltrated with molten paraffin wax. Sections of $5 \mu$ thick were made from the embedded tissues using a microtome, both the longitudinal and cross sections were obtained. The sections were then mounted on grease free glass slides and stained with Haematoxylin and Eosin (H\&E) stain for routine histological studies (Drury and Wallington, 1980). The slides were examined using a light microscope Olympus, CHB made in Tokyo Japan. All variables were studied at varying magnifications. Photographs of the tissues were taken using AmScope MT series Microscope Camera connected to a computer.

\section{Statistical analysis}

Levene's test of homogeneity of variance was conducted to evaluate the assumption of equality of variances (Colon weight and length, body weight and length). Post-hoc comparisons using Tukey's HSD test were conducted. The one-way analysis of variance was done to ascertain the significance of colon length and weight with age and crypth height and width with age.

\section{Results}

\section{Gross observations}

The colon of albino rat was observed to be attached to the caecum proximally. The most cranial segment was identified as the ascending colon which ran towards the thoracic cavity extending from the left to right sides to form the transverse colon, and then the descending colon which ran from the side of the liver downwards to the rectum.

\section{Gross Morphometry}

The weights and lengths of colon were ascending with age. Statistical analysis revealed that there are significant $(\mathrm{P}<0.011)$ differences in the lengths and weights between the age groups of albino rats studied. Post-hoc comparisons using Games Howell's test indicated that the mean weight among experiment specimen in the Group 1 (Two Month) $(M=29.82, S E M=0.80)$ was significantly lower compared to mean weight in the Group 2 (four months) $(M=72.48$, $S E M=4.74)$ and Group 3 (Six month) $(M=198.00, S E M=$ 2.00). Also, Group 2 (four months) was significantly lower compared to group 3 and higher compared to Group 1 (Table $1)$.

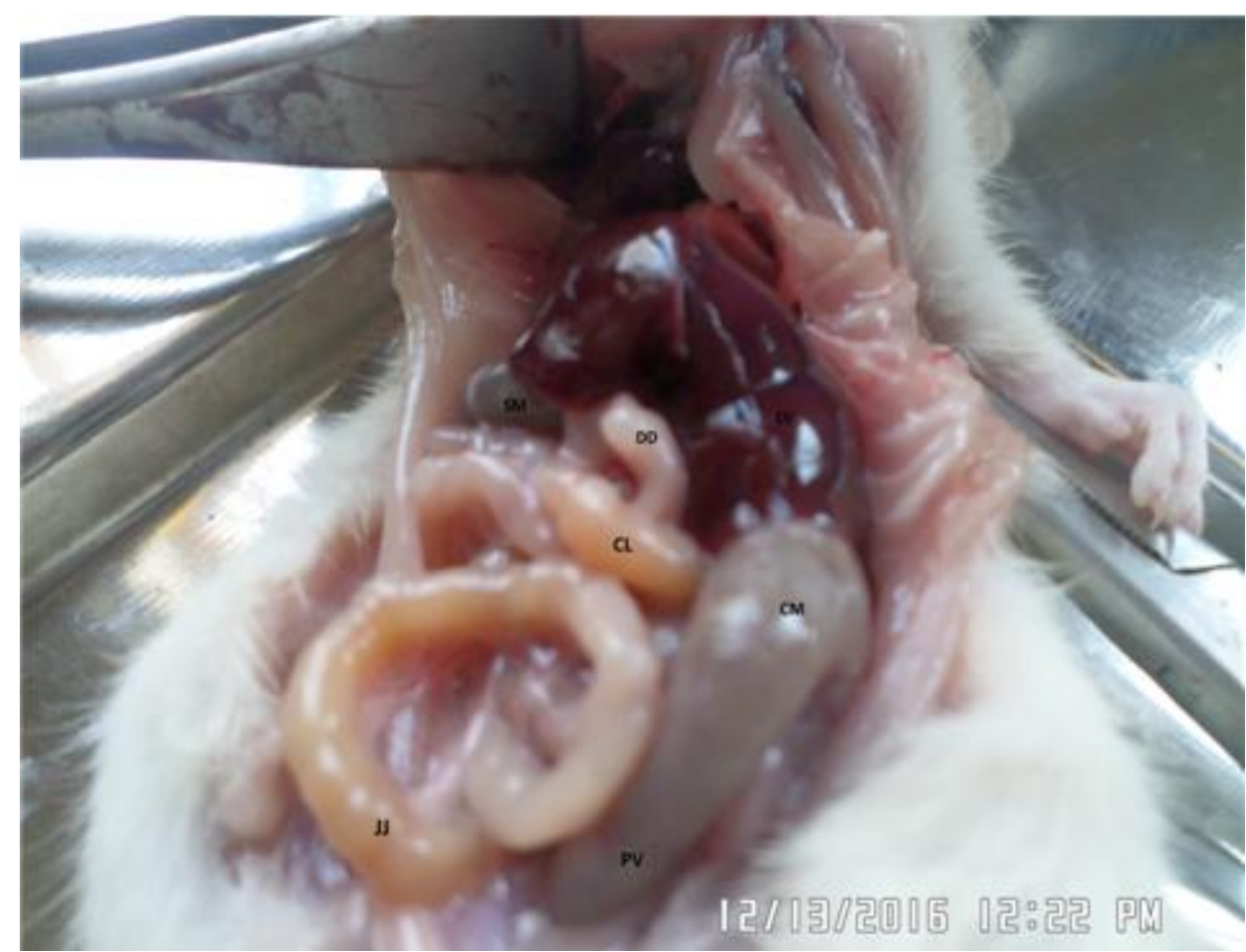

Picture 1: Abdominal of female albino rat cavity showing liver (LV), stomach (SM), duodenum (DD), colon (CL), jejunum $(\mathrm{JJ})$, caecum $(\mathrm{CM})$ and processus vermiformis $(\mathrm{PV})$

The length and weight of albino rat colon varied across the age groups as shown in Table 1. 


\section{International Journal of Science and Research (IJSR) \\ ISSN (Online): 2319-7064 \\ Index Copernicus Value (2015): 78.96 | Impact Factor (2015): 6.391}

Table 1: One-Way Analysis of Variance for Colon Weight and Length as express as Mean \pm SEM

\begin{tabular}{|c|c|c|c|c|}
\hline & Two Month & Four Month & Six Month & $P$ \\
\hline $\begin{array}{c}\text { Colon } \\
\text { Weight }(\mathrm{g})\end{array}$ & $1.16 \pm 0.17^{*}$ & $1.07 \pm 0.03^{*}$ & $2.62 \pm 0.07^{*}$ & $<0.001$ \\
\hline $\begin{array}{c}\text { Colon } \\
\text { Length }(\mathrm{cm})\end{array}$ & $12.12 \pm 0.10^{*}$ & $14.25 \pm 0.25^{*}$ & $19.10 \pm 0.46^{*}$ & $<0.001$ \\
\hline
\end{tabular}

All rows sharing the same superscript are significantly $(P=$ $0.05)$ different.

\section{Body Length on arrival}

Post-hoc comparisons using Games Howell's test were conducted. The results indicated that the mean body length among experiment specimen in the Group A (Two Month) $(M=20.10, S E M=0.0)$ was significantly lower compared to mean body length in the Group B (Four Month) $(M=24.55$, $S E M=0.85)$ and Group C (Six month) $(M=30.50, S E M=$ 0.16). Also Group B was significantly lower compared to group $\mathrm{C}$ and higher compared to Group A (Table 2).

Table 2: One-Way Analysis of Variance for Weight and body length on arrival as express as Mean \pm SEM

\begin{tabular}{|c|c|c|c|c|}
\hline & Two Month & Four Month & Six Month & $P$ \\
\hline Weight (g) & $29.82 \pm 0.80 *$ & $72.48 \pm 4.74 *$ & $198.00 \pm 2.00 *$ & $<0.001$ \\
\hline $\begin{array}{c}\text { Body } \\
\text { Length (cm) }\end{array}$ & $20.10 \pm 00 *$ & $24.55 \pm 0.85 *$ & $30.50 \pm 16^{*}$ & 0.001 \\
\hline
\end{tabular}

All rows sharing the same superscript are significantly $(P=$ 0.05 ) different.

\section{Weight and Body Length on sacrifices}

\section{Weight (g)}

Levene's test of homogeneity of variance was conducted to evaluate the assumption of equality of variances. The results of Levene's test were significant $F(2,11)=6.28, P=0.015$. The one-way analysis of variance was statistically significant, $F(2,4)=127.68, p=<0.001$. Post-hoc comparisons using Games Howell's test were conducted. The results indicated that the mean weight among experiment specimen in the Group A (Two Month) $(M=$ $50.00, S E M=0.0)$ was significantly lower compared to mean weight in the Group B (Four Month) $(M=100.0, S E M$ $=0.0$ and Group C (Six month) $(M=290.0, S E M=0.0)$. Also Group 2 was significantly lower compared to group 3 and higher compared to Group 1 (Table 2).

\section{Body length (cm)}

Levene's test of homogeneity of variance was conducted to evaluate the assumption of equality of variances. The results of Levene's test were significant $F(2,11)=4.62, P=0.035$. The one-way analysis of variance was statistically significant, $F(2,4.02)=100.41, p=<0.001$. Post-hoc comparisons using Games Howell's test were conducted. The results indicated that the mean body length among experiment specimen in the Group A (Two Month) $(M=$ $24.60, S E M=0.29)$ was significantly lower compared to mean body length in the Group B (Four Month) $(M=28.0$, $S E M=1.0)$ and Group C (Six month) $(M=35.90, S E M=$ 0.25 ). Also, Group B was significantly lower compared to group $\mathrm{C}$ and higher compared to Group A (Table 2).
Table 2: One-Way Analysis of Variance for Weight and body length on sacrifices as expressed as Mean \pm SEM

\begin{tabular}{|c|c|c|c|c|}
\hline & Two Month & Four Month & Six Month & $P$ \\
\hline Weight $(\mathrm{g})$ & $50.0 \pm 00^{*}$ & $100.0 \pm 0.0^{*}$ & $290.0 \pm 0.0^{*}$ & $k 0.001$ \\
\hline $\begin{array}{c}\text { Body } \\
\text { Length }(\mathrm{cm})\end{array}$ & $24.60 \pm 0.29^{*}$ & $28.00 \pm 1.00^{*}$ & $35.90 \pm 0.25^{*}$ & 0.001 \\
\hline
\end{tabular}

All rows sharing the same superscript are significantly $(P=$ $0.05)$ different.

\section{Crypt Height}

Table 3: One-Way Analysis of Variance for Crypt height of colon as expressed as Mean \pm SEM

\begin{tabular}{|c|c|c|c|c|c|}
\hline & Mean \pm SEM & Min. & Max. & $\boldsymbol{F}$ & $\boldsymbol{P}$ \\
\hline A & $65.80 \pm 4.40$ & 52.88 & 72.64 & 52.89 & $<0.001$ \\
\hline B & $99.32 \pm 3.49$ & 94.07 & 109.57 & & \\
\hline C & $116.67 \pm 2.53$ & 110.24 & 121.14 & & \\
\hline
\end{tabular}

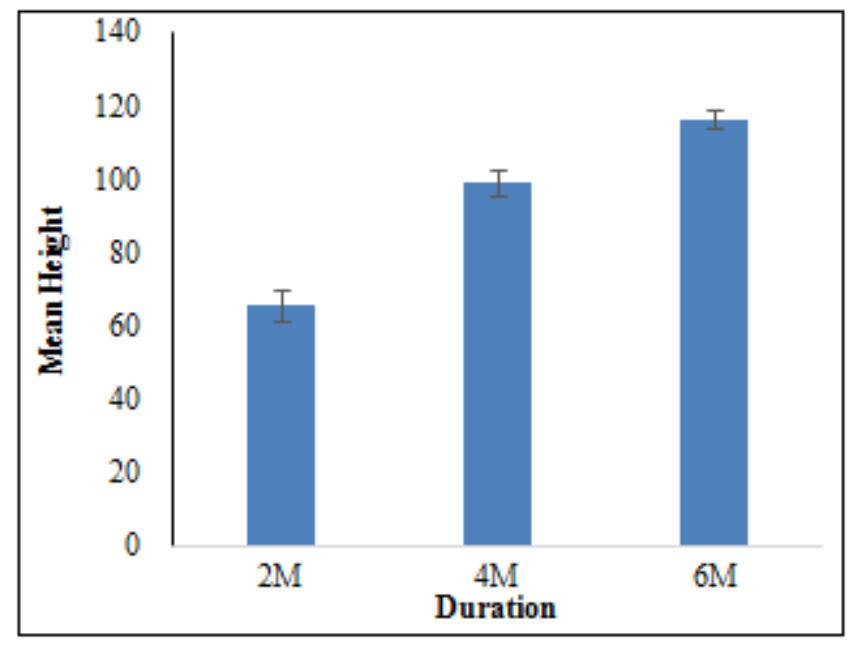

\section{Crypt Width}

Levene's test of homogeneity of variance was conducted to evaluate the assumption of equality of variances. The results of Levene's test were not significant. The one-way analysis of variance was statistically significant, $F(2,9)=10.09, p=$ 0.005. Post-hoc comparisons using Turkey's HSD test were conducted. The results indicated that the mean Crypt width among experiment specimen in the Group1(Two Month) ( $M$ $=10.31, S E M=0.38$ ) was significantly lower compared to mean Crypt height in the Group 2(Four Month) $(M=14.37$, $S E M=1.19)$ and Group 3(Six month) $(M=16.74, S E M=$ 1.26). also Group 2 was significantly lower compared to group 3 and higher compared to Group 1 (Table 2).

Table 4: One-Way Analysis of Variance for Crypt width of colon as expressed as Mean \pm SEM

\begin{tabular}{|c|c|c|c|c|c|}
\hline & Mean \pm SEM & Min. & Max. & $\boldsymbol{F}$ & $\boldsymbol{P}$ \\
\hline A & $10.31 \pm 0.38$ & 9.28 & 10.95 & 10.09 & 0.005 \\
\hline B & $14.37 \pm 1.19$ & 12.63 & 17.76 & & \\
\hline C & $16.74 \pm 1.26$ & 13.13 & 18.86 & & \\
\hline
\end{tabular}




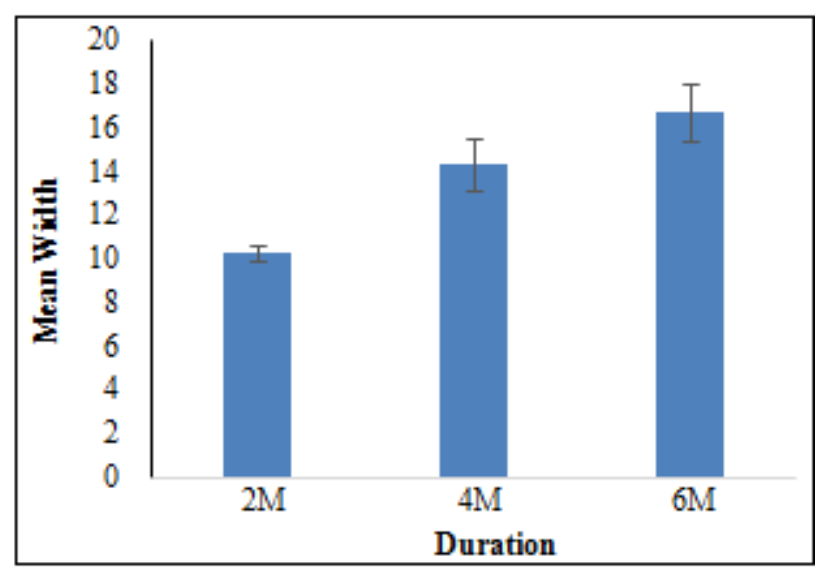

\section{Discussion}

Knowledge of intestinal morphometry is useful in studying absorption of nutrients in different species. Grossly, the length of colon reported in this study was $12.12 \pm 0.10 \mathrm{~cm}$, $14.25 \pm 0.25 \mathrm{~cm}$ and $19.10 \pm 0.46 \mathrm{~cm}$ for two months, four months and six months old albino rats respectively (Table 1). This finding differs from that obtained by Katarina et al. (2016) who reported the colon length of wistar rat aged one year to be between $95-100 \mathrm{~mm}$. This variation has been attributed to the fact that postnatal development and structure of the gastrointestinal tract is affected by a number of factors including diet, genetic determinants and hormones (Warthall et al., 2005). The length of colon was found to be directly proportional to body length and weight. It can be inferred that intestinal growth and intestinal cell proliferation are associated with increased absorption with age. From the histomorphometry of the colon, we found that crypt length and breadth also increased with age.

Morphometric analysis is widely used in gastrointestinal research, since it is a quantitative assessment and thus more reliable and reproducible than a subjective assessment, which is especially important in the diagnosis of different pathological conditions not readily apparent during routine histological assessment. For example, computerized image analysis has been used to discriminate between various types of inflammatory bowel disease.

\section{References}

[1] Brunet, A., Berger, S. L. (2014). Epigenetics of aging and aging-related disease. Journal of Gerontology A Biol. Sci. Med. Sci. 69.

[2] Fodde, R. (2002). The APC gene in colorectal cancer. European Journal of Cancer, 38: 867- 871.

[3] Finch CE (1990). Longevity, Senescence, and the Genome. The University of Chicago Press, Chicago/London.

[4] Kennedy, B. K., Berger, S. L., Brunet, A., Campisi, J., Cuervo, A. M., Epel, E. S., Franceschi, C., Lithgow, G. J., Morimoto, R. I., Pessin, J. E., Rando, T. A., Richardson, A., Schadt, E. E., Wyss-Coray, T. and Sierra, F. (2014). Geroscience: Linking aging to chronic disease. Cell, $159 ;$ 709-713.

[5] Mural, R.J., Adams, M.D., Myers, E.W., Smith, H.O., Miklos, G. L., Wides, R. and Halpern, A. (2002). A comparison of whole-genome shotgun-derived mouse chromosome 16 and the human genome. Science, 296: 1661-1671.

[6] Nordgaard, I. (1998). Colon as a digestive organ: the importance of colonic support for energy absorption as small bowel failure proceeds. Dan Medical Bulletin, 45:135-56

[7] Rattan, S.I. (1995). Gerontogenes: real or virtual? Faseb Journal, 9: 284-286

[8] Rombeau, J.L. (2003). Rethinking the human colon: a dynamic metabolic organ. Contemporary Surgery, 59:450-452.

[9] Salmon, A.B., Richardson, A. and Pérez, V.I. (2010). Update on the oxidative stress theory of aging: does oxidative stress play a role in aging or healthy aging? Free Radical Biology and Medicine, 48: 642-655

[10] Tjalsma,H., Boleij, A., Marchesi, J.R. and Dutilh, B.E. (2012). A bacterial driver-passenger model for colorectal cancer: beyond the usual suspects Nat Rev Microbiol, 10 (2012), pp. 575-582

[11] Walthall, K., Cappon, G.D., Hurtt, M. E. and Zoetis, T. (2005). Postnatal Development of the gastrointestinal system: A species comparision. Birth Defects Resource (Part B), 74: 132- 156 